\title{
APPLICATION OF FUZZY CRITICAL PATH METHOD TO AIRPORTS CARGO GROUND OPERATION SYSTEMS
}

\author{
Tzeu-Chen Han \\ Associate Professor, Department of Shipping and Transportation Management, National Penghu University, 300, Liu- \\ Ho Road, Ma-Kung, Penghu, Taiwan, R.O.C. \\ Cheng-Chi Chung \\ Assistant Professor, Department of Shipping and Transportation Management, National Taiwan Ocean University, 2, \\ Pei-Ning Road, Keelung, Taiwan 202, R.O.C., jackie@mail.ntou.edu.tw \\ Gin-Shuh Liang \\ Professor, Department of Shipping and Transportation Management, National Taiwan Ocean University, 2, Pei-Ning \\ Road, Keelung, Taiwan 202, R.O.C.
}

Follow this and additional works at: https://jmstt.ntou.edu.tw/journal

Part of the Business Commons

\author{
Recommended Citation \\ Han, Tzeu-Chen; Chung, Cheng-Chi; and Liang, Gin-Shuh (2006) "APPLICATION OF FUZZY CRITICAL PATH METHOD \\ TO AIRPORTS CARGO GROUND OPERATION SYSTEMS," Journal of Marine Science and Technology. Vol. 14: Iss. 3, \\ Article 2. \\ DOI: $10.51400 / 2709-6998.2067$ \\ Available at: https://jmstt.ntou.edu.tw/journal/vol14/iss3/2 \\ This Research Article is brought to you for free and open access by Journal of Marine Science and Technology. It has been \\ accepted for inclusion in Journal of Marine Science and Technology by an authorized editor of Journal of Marine Science and \\ Technology.
}




\title{
APPLICATION OF FUZZY CRITICAL PATH METHOD TO AIRPORT'S CARGO GROUND OPERATION SYSTEMS
}

\author{
Tzeu-Chen Han*, Cheng-Chi Chung**, and Gin-Shuh Liang***
}

Key words: fuzzy critical path analysis, fuzzy set theory, airport's ground operation system.

\section{ABSTRACT}

To cut down cost in a competitive environment, airlines must avoid delays and operation inefficiencies in both airside and landside. However, previous studies have paid little attention to an airlines' ground operation in airports' cargo terminals. The purpose of this paper is to demonstrate how to employ the Fuzzy Critical Path method (CPM) to find out airport's ground critical operation processes and improve. The result of this study suggests redesigning airports' cargo handling processes can improve airlines' freight service performance in terms of freight handling speed, cargo service quality, and freight handling cost in hub airports.

\section{INTRODUCTION}

Since the terrorist attack in United States on September 11th and the convulsions of SARS (serious acute respiratory tract syndrome) crisis in Asia, airports are confronted with a fundamental business challenge survival and success in a turbulent and increasingly competitive environment. Several troubling signs are already in place. Airline stays are shortening: airline closures and market concentration are increasing, and excess capacity continues to remain a topic of serious concern for most airports [15, 26, 27]. Airports managers have to increase their freight terminals' utilization/ occupancy rates and reduce their airlines' ground operation costs to survive. However, airport managers do

Paper Submitted 08/23/05, Accepted 12/06/05. Author for Correspondence: Cheng-Chi Chung. E-mail: jackie@mail.ntou.edu.tw.

*Associate Professor, Department of Shipping and Transportation Management, National Penghu University, 300, Liu-Ho Road, Ma-Kung, Penghu, Taiwan, R.O.C.

**Assistant Professor, Department of Shipping and Transportation Management, National Taiwan Ocean University, 2, Pei-Ning Road, Keelung, Taiwan 202, R.O.C.

***Professor, Department of Shipping and Transportation Management, National Taiwan Ocean University, 2, Pei-Ning Road, Keelung, Taiwan 202, R.O.C. not pay enough attentions on these two topics currently. Products in transportation industry are different from products in general commodity industry.

Passengers seats and cargoes space cannot be kept and are perished once a ship or an airplane is departured, and airlines have to plan their passenger seats and cargo space efficiently to meet their customers' peak time demand. By the same token, airports' terminal capacity (in both landside and airside) cannot be kept in low season and sell them in the next high season. The transportation service industry has other characteristics which must be carefully considered throughout the years; namely, traffic demands in high and low seasons, heavy traffic demands on certain days of each month or week, and peak/off-peak hours on every day of the week. With most airports operating on low utilization rates in offpeak hours and high utilization rates in peak hours, it is important to find out why airlines choose to call at some airports and not others. This is not a mere desire, but a necessity. In current competitive market, only those airports with a clear understanding of how to cut their users' ground operation time and costs will be able to thrive.

In the past decade many scholars have probed how to avoid the delays and inefficiencies experienced in airside, landside, and airlines' operations to cut down airlines' cost [12, 21, 22]. Airlines that want change usually incur extra capital expenditures. Even though the fore-mentioned researchers have solved airlines' scheduling problems, serious obstacles remain within the airlines in respect to ground operations. Inadequate operating processes in an airport's cargo terminals can reduce its operation efficiency; hence it will increase an airport's (specifically a hub airport) stakeholders' running cost [25]. Hub airports (/hubs) are gaining prominence as transferring passengers opting for cheaper tickets, creating delays and operation bottlenecks at peak times. Therefore, it is deemed essential for airlines to take the operating procedures of terminals into serious account [17]. According the authors' knowledge, previous studies have focused their researches on ground 
operations in airside only, study on landside is not found.

Hansen [12] used a deterministic queuing model to explore conflicts between departing or landing aircraft delayed on runways and those following them at Los Angeles international airport. Yan et al. [22] who used Chiang Kai-Shek (CKS) international airport as an example explored the take off and landing operational delays to draft a systematized simulation in order to help develop the best active arrival gate pattern in the situation of conflicting flight schedules. Wu and Caves [21], who looked at European airplane scheduling, used an aircraft turnaround model and an enroute model of needed time between two airports to research the best aircraft rotation model, in order to provide a reference study for airline companies negotiating a scheduling plan for a number of airports.

Barrett [3] studied 17 European airports' management strategies after the EU's open sky and airline deregulation policy in 1992. In order to increase their competitiveness, most airport authorities utilized higher airport service quality and sought the patronage of lowfare airlines to attract more passengers. Mohleji [16] analyzed the work processes of air traffic approach control to regulate route-oriented planning and control procedure to maintain the smooth air traffic flow and reduce airplanes' delays in takeoff and landing. Bolat [4] used a mixed binary mathematical model to research the best gate arrangement to improve the utilization rate of airport gates and the time needed for airplane movement upon landing at an airport.

Surprisingly, scholars have strangely neglected the study of airport ground operations. The remainder of the paper describes the framework, explains fuzzy set theory and fuzzy critical path method (CPM), presents the method and findings of an empirical study, and proffers the concept derived from the study findings.

\section{FRAMEWORK}

The peak and valley phenomenon is very apparent in transport enterprises. Small differences in the increase numbers of passengers at peak times will greatly affect the level of service offered by airline companies, especially in the service areas of airport terminals [9]. In addition, a shortage of working personnel can result in lengthy processing times, due to the discrepancies between boarding times for passengers, the different types of boarding passengers, and the limits for which airline companies can plan. A shortage of working personnel or work delays described above can not only lead to boarding passengers developing an unfavorable image of the airline companies, but delayed flights as well. These factors can lower the airport landing slot usage rate and lower the general effectiveness of the airport's management for the airport authorities.

However, not all of the airports' peak times are like this, since only some will face large volumes of traffic at certain peak times, which will then create the problem of facilities and service personnel being overextended [1]. If airport authorities are unable to handle problems in airport facilities at peak times or provide sufficient manpower, major management problems can arise. Through changing work processes or using different transport management strategies in a limited space, hopefully customer complaints will be kept to a minimum, as well as employing the simplest, cheapest yet most time-saving methods for a given period of time [8]. The airlines passenger and cargo ground handling time in many international airports is instable [9].

In order to improve this instability, the first step is to identify all steps so that the most time-consuming step can be found. By reducing process time required in the most time-consuming step, the airlines' ground operation efficiency can be improved. In reality, it is often difficult to obtain estimates of activity time, due to the uncertainty of information as well as variation in the management scenario of air transportation, specifically air hubs' ground operations. Moreover, linguistic terms such as "approximately between 1 and 2 hours" and "around 1.5 hours" are frequently used to convey their estimations [24]. These conventional approaches, both deterministic and random process, tend to be less effective in conveying the imprecise or vague nature of these linguistic assessments [6, 18]. Fuzzy set theory [23] can play a significant role in this kind of decisionmaking environment. Nasution [18] proposed a fuzzy critical path method by considering interactive fuzzy subtraction and by observing that only the non-negative part of the fuzzy numbers can have physical interpretation. Chanas and Zielinski [6] proposed a method to undertake critical path analysis (CPA) of the network with fuzzy activity times (interval activity times, fuzzy numbers of the L-R type) by directly applying the extension principle [16] to the classical criticality notion treated as a function of activity duration time in the network. Slyeptsov and Tyshchuk [19] presented an efficient computation method of fuzzy time windows for late start and finish times of operations in the fuzzy network problems.

Fuzzy set theory is used to tackle problems where a source of vagueness is involved. Linguistic terms can be properly represented by the approximate reasoning of fuzzy set theory [24]. To effectively deal with the ambiguities involved in the process of linguistic estimate times, Liang and Han [14] used the trapezoidal fuzzy numbers to make the fuzzy measures of activity times characterized by linguistic values, and proposed 
an algorithm for finding the fuzzy critical path of a project network. Liang and Han's [14] method reduce the complexity of airport's ground operation model development and computations for solving problems, as well as incorporate the decision-maker's risk attitude into the decision process. Thus this method is utilized to perform critical path analysis for the CKS airport's ground operation network.

\section{THE REPRESENTATION OF FUZZY ACTIVITY TIME}

In this paper, the fuzzy activity time, denoted by $F E T_{i j}$, of activity $A_{i j}$ in a project network is represented by trapezoidal fuzzy number $F E T_{i j}=\left(c_{i j}, a_{i j}, b_{i j}, d_{i j}\right)$ $[1,17]$, where $c_{i j}, d_{i j}$ are minimum and maximum values of assessing activity time for $A_{i j}$, whereas $a_{i j}$ and $b_{i j}$ are the first quartile and third quartile of activity time for $A_{i j}$. If there is only one set of four historical data, then $c_{i j}, a_{i j}, b_{i j}, d_{i j}$ can be sorted from minimum to maximum. For example, if the current four historical data of activity are $6,9,3$, and 8 , the trapezoidal fuzzy number of evaluation value is $(3,6,8,9)$. Conversely, if one has no further information with respect to activity $A_{i j}$, the fuzzy activity time $F E T_{i j}=\left(c_{i j}, a_{i j}, b_{i j}, d_{i j}\right)$ can be evaluated subjectively by the decision-maker based on his/her knowledge, experience and subjective judgment.

Applying the extension principle [19], the extended algebraic operations of any two fuzzy activity times and can be expressed as:

Addition $\oplus$ :

$$
\begin{aligned}
F E T_{1} \oplus F E T_{2} & =\left(c_{1}, a_{1}, b_{1}, d_{1}\right) \oplus\left(c_{2}, a_{2}, b_{2}, d_{2}\right) \\
& =\left(c_{1}+c_{2}, a_{1}+a_{2}, b_{1}+b_{2}, d_{1}+d_{2}\right)
\end{aligned}
$$

Subtraction $\ominus$ :

$$
\begin{aligned}
F E T_{1} \ominus F E T_{2} & =\left(c_{1}, a_{1}, b_{1}, d_{1}\right) \ominus\left(c_{2}, a_{2}, b_{2}, d_{2}\right) \\
& =\left(c_{1}-d_{2}, a_{1}-b_{2}, b_{1}-a_{2}, d_{1}-c_{2}\right)
\end{aligned}
$$

\section{THE RANK OF TRAPEZOIDAL FUZZY NUMBER}

Ranking methods are essential in fuzzy CPM. Many methods of ranking fuzzy numbers have been proposed. However, certain shortcomings in some of those methods have been reported by Bortolan and Degani [5], Chen [7] and Kim and Park [13]. For ease of implementation, a useful ranking method developed by Liang and Han [14] is utilized to tackle ranking problems existing in fuzzy path analysis. Let $F E T_{i j}=\left(c_{i j}, a_{i j}, b_{i j}, d_{i j}\right)$ be the fuzzy activity time of activity $A_{i j}$. The decision maker's risk attitude index $\beta$ can be obtained by

$$
\beta=\left[\sum_{\substack{i \in j \\ A_{i j} \in A C T}} \frac{a_{i j}-c_{i j}}{\left(a_{i j}-c_{i j}\right)+\left(d_{i j}-b_{i j}\right)}\right] / t
$$

where $A C T$ and $t$ denote the set of all activities and the number of activities in an airport's ground operation network.

For a fuzzy number $A_{i}$ with membership functions $f_{A_{i}}(x)$ we define

$$
m_{i}=\min \left\{x \mid f_{A_{i}}(x)=1\right\}+\max \left\{x \mid f_{A_{i}}(x)=1\right\} .
$$

Now, we rank the fuzzy numbers $A_{i}$ and $A_{j}$ according to the following rules:

$$
\begin{aligned}
& A_{i}>A_{j} \Leftrightarrow R\left(A_{i}\right)>R\left(A_{j}\right), \text { or, } \\
& R\left(A_{i}\right)=R\left(A_{j}\right) \text { and } m_{i}>m_{j}, \\
& A_{i}=A_{j} \Leftrightarrow R\left(A_{i}\right)=R\left(A_{j}\right) \text { and } m_{i}=m_{j}
\end{aligned}
$$

Then, the ranking value $R\left(A_{i}\right)$ of the trapezoidal fuzzy number $A_{i}$ can be obtained as follows:

$$
\begin{aligned}
R\left(A_{i}\right) & =\beta\left[\left(d_{i}-x_{1}\right) /\left(x_{2}-x_{1}-b_{i}+d_{i}\right)\right] \\
& +(1-\beta)\left[1-\left(x_{2}-c_{i}\right) /\left(x_{2}-x_{1}+a_{i}-c_{i}\right)\right]
\end{aligned}
$$

Where $\beta$ is the decision maker's risk attitude index, $x_{1}=\min \left\{c_{1}, c_{2}, \ldots, c_{n}\right\}$, and $x_{2}=\max \left\{d_{1}, d_{2}, \ldots, d_{n}\right\}$.

By using Eq. (2) and taking the $\beta$ value calculated by Eq. (1), one can easily calculate the ranking values of the $n$ trapezoidal fuzzy numbers. Based on the ranking rules described above, the ranking of the $n$ trapezoidal fuzzy numbers can then be effectively determined.

\section{FUZZY CRITICAL PATH METHOD}

\section{Notations}

$N=$ The set of all nodes in a project network.

$A_{i j}=$ The activity between nodes $i$ and $j$.

$F E T_{i j}=$ The fuzzy activity time of $A_{i j}$.

$F E S_{j}=$ The earliest fuzzy time of node $j$.

$F L F_{j}=$ The latest fuzzy time of node $j$.

$F T S_{i j}=$ The total slack fuzzy time of $A_{i j}$.

$S(j)=$ The set of all successor activities of node $j$.

$N S(j)=$ The set of all nodes connected to all successor activities of node $j$, i.e., $N S(j)=\left\{k \mid A_{j k} \in S(j), k\right.$ $\in N\}$.

$F(j)=$ The set of all predecessor activities of node $j$. 
$N P(j)=$ The set of all nodes connected to all predecessor activities of node $j$, i.e., $N P(j)=\left\{i \mid A_{i j} \in F(j)\right.$, $i \in N\}$.

$P_{i}=$ The $i$-th path.

$P=$ The set of all paths in a project network.

$\operatorname{FCPM}\left(P_{k}\right)=$ The total slack fuzzy time of path $P_{k}$ in a project network.

\section{The important properties and theorem in FCPM}

In here, the important properties and theorem used in the fuzzy CPM [14] are briefly introduced. Set the initial node to zero for starting, i.e., $F E S_{1}=(0,0,0,0)$. Then, the following properties are true.

Property $1 F E S_{j}=\max \left\{F E S_{i} \oplus F E T_{i j} \mid i \in N P(j)\right.$, $j \neq 1, j \in N\}$

Property $2 F L F_{j}=\min \left\{F L F_{k} \ominus F E T_{j k} \mid k \in N S(j)\right.$, $j \neq n, j \in N\}$

Property $3 F T S_{i j}=F L F j \ominus\left(F E S_{i} \oplus F E T_{i j}\right)$, $1 \leq i<j \leq n ; i, j \in N$

$$
\text { Property } 4 \operatorname{FCPM}\left(P_{K}\right)=\sum_{\substack{1 \leq i<j \leq n \\ i, j \in P_{K}}} F T S_{i j}, P_{K} \in P
$$

In an airport's operation network, a path $P_{C}$ such that

$$
\operatorname{FCPM}\left(P_{C}\right)=\min \left\{F C P M\left(P_{i}\right) \mid P_{i} \in P\right\}
$$

is a fuzzy critical path. Thus, the theorem stated as below is true.

\section{Theorem 1}

Assume that the fuzzy activity times of all activities in an airport's ground operation network are trapezoidal fuzzy numbers; then there exists a fuzzy critical path in the network [14].

\section{Algorithm}

In this section, a fuzzy critical path algorithm [14] is utilized to find a critical path of an airport's ground operation network in a fuzzy environment. The description of the algorithm is presented in the following.

Fuzzy critical path algorithm:

1. Identify activities in an airport's ground operation.

2. Establish precedence relationships of all activities.

3. Estimate the fuzzy activity time with respect to each activity.

4. Construct the airport's ground operation network.

5. Let $F E S_{1}=(0,0,0,0)$ and calculate $F E S_{j}, j=2,3, \ldots$, $n$, by using property 1 .
6. Let $F L F_{n}=F E S_{n}$ and calculate $F L F_{j}, j=n-1, n-$ $2, \ldots, 2,1$, by using property 2 .

7. Calculate $F T S_{i j}$ with respect to each activity in an airport's ground operation network by using property 3.

8. Find all the possible paths and calculate $F C P M\left(P_{k}\right)$ by using property 4.

9. Find the fuzzy critical path by using theorem 1 .

10. Find the grade of membership so that the airport's ground operation can be completed at the scheduled time.

\section{EMPIRICAL STUDY}

Baker and O'toole [2] indicated that the major airlines are combination carriers in main Asian airports, the top 10 international airports worldwide, as well as in Taiwan's Chiang Kai-Shek (CKS) international airport. According to Zhang et al. [27], Han et al. [11] Forster and Regan [10] most international airfreight businesses in a complete air cargo business carry goods only by common carriers, especially in Asia. As a previous section has indicated, most international passenger businesses are conducted at the hubs [17, 25]. As the volume of cargo traffic has grown and the demand for cargo transport continues to rise, surface congestion has become an increasing problem, especially within an airport's cargo terminal. Moreover, if an airport terminal's internal operations and service systems are inefficient, or operational procedures are insufficiently detailed, there will be a delay in ground operations contributing to flight delays for airlines which may prove very costly in the long-run [1]. Since the combination carriers' main revenue is from passenger transportation, they will carry passengers as well as their baggage first. Therefore, cargo operations' time needs to be shortened and passengers' luggage must be processed before cargo goods in order to maintain customer satisfaction $[1,20]$. To raise the profitability, efficiency of the airport cargo terminal, and to increase overall competitiveness; use of fuzzy CPA will easily find out the critical path. Based on this concept, this study uses Taiwan's Chiang Kai-Shek (CKS) international airport cargo terminal's ground operation procedures as an example in order to demonstrate the computational process of the fuzzy CPA proposed above. Combination carriers' cargo handling processes from shippers to receivers are summarized as follows:

Sender $\rightarrow$ Freight forwarders responsible for the operation on the ground process the related exportimport documents $\rightarrow$ goods are sent to the International airport warehouse $\rightarrow$ A check on import or export items is carried out by the relevant government agency, with cargo terminal personnel handling stocking and pack- 
aging $\rightarrow$ combination carrier handles the transportation, with ground crew contractors to handle the load operation $\rightarrow$ goods arrive at destination and are unloaded by the ground crew $\rightarrow$ International airport cargo terminal process and itemize the goods $\rightarrow$ Related documents are processed and custom duties are paid $\rightarrow$ the Freight forwarders handle customs duties and arranges and schedules deliveries $\rightarrow$ goods are delivered to the consignees.

After 8 months observing and identifying all cargo export steps associated with the process the quantitative relevant fuzzy activity times are collected to support the observations. Figure 1 shows CKS international airport cargo terminal's ground operation procedures network. With the set of node $N=\{1,2,3,4,5\}$, the fuzzy activity time for each activity is shown in Table 1, and all of the durations are in minutes.

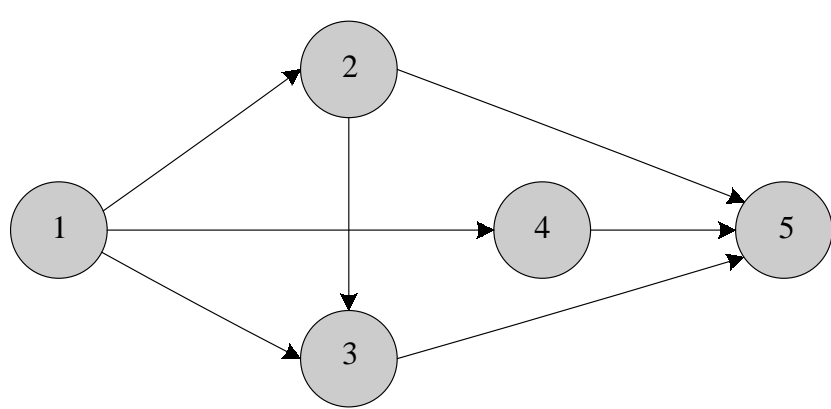

Fig. 1. The ground operation of CKS international airport cargo terminal network. 0.5306 .

By using Eq. (1), the total risk index $\beta$ is equal to

Step 1. Set $F E S_{1}=(0,0,0,0)$ and calculate $F E S_{j}, j=2$, $3,4,5$ by using property 1 .

$$
\begin{aligned}
F E S_{2} & =F E S_{1} \oplus F E T_{12}=(0,0,0,0) \oplus(10,15,15,20) \\
& =(10,15,15,20) \\
F E S_{3} & =\max \left\{F E S_{1} \oplus F E T_{13}, F E S_{3} \oplus F E T_{23}\right\} \\
& =\max \{(30,40,40,50),(40,55,65,80)\}
\end{aligned}
$$

by Eq. (1) and taking $\beta=0.5306$, the ranking value of $(30,40,40,50)$ and $(40,55,65,80)$ can be obtained: $x_{1}$ $=30, x_{2}=80$,

$$
\begin{aligned}
& R((30,40,40,50)) \\
& \quad=0.5306[(50-30) /(80-30-40+50)] \\
& \quad+0.4694[1-(80-30) /(80-30+40-30] \\
& \quad=0.2551, \\
& R((40,55,65,80)) \\
& \quad=0.5306[(80-30) /(80-30-65+80)] \\
& \quad+0.4694[1-(80-40) /(80-30+55-40)] \\
& \quad=0.5887,
\end{aligned}
$$

\begin{tabular}{|c|c|c|}
\hline Activity $A_{i j}$ & Description & Fuzzy activity time (Minutes) $F E T_{i j}$ \\
\hline$A_{12}$ & $\begin{array}{l}\text { Customs office cargo clearance with document approval } \\
\text { (Named C2) }\end{array}$ & Approximately 15 minutes $(10,15,15,20)$ \\
\hline$A_{13}$ & $\begin{array}{l}\text { Customs office cargo clearance with inspection } \\
\text { (Named C3) }\end{array}$ & Approximately 40 minutes $(30,40,40,50)$ \\
\hline$A_{23}$ & $\begin{array}{l}\text { Customs office cargo clearance with document approval } \\
\text { and inspection (Named C2, C3) }\end{array}$ & $\begin{array}{l}\text { Approximately between } 30 \text { and } 60 \text { minutes } \\
(30,40,50,60)\end{array}$ \\
\hline$A_{14}$ & $\begin{array}{l}\text { Customs office inspection-exempt cargo clearance } \\
\text { (Named C1) }\end{array}$ & $\begin{array}{l}\text { Approximately between } 15 \text { and } 30 \text { minutes } \\
(15,20,25,30)\end{array}$ \\
\hline$A_{25}$ & $\begin{array}{l}\text { Customs office after cargo clearance with document } \\
\text { approval, releasing cargo and packing cargo waiting } \\
\text { for loading. }\end{array}$ & $\begin{array}{l}\text { Approximately between } 60 \text { and } 180 \text { minutes } \\
(60,100,150,180)\end{array}$ \\
\hline$A_{35}$ & $\begin{array}{l}\text { Customs office after cargo clearance with inspection, } \\
\text { releasing cargo and packing cargo waiting for loading. }\end{array}$ & $\begin{array}{l}\text { Approximately between } 60 \text { and } 180 \text { minutes } \\
(60,100,150,180)\end{array}$ \\
\hline$A_{45}$ & $\begin{array}{l}\text { Customs office after inspection-exempt cargo clearance, } \\
\text { releasing cargo and packing cargo waiting for loading. }\end{array}$ & $\begin{array}{l}\text { Approximately between } 60 \text { and } 180 \text { minutes } \\
(60,100,150,180)\end{array}$ \\
\hline
\end{tabular}

Since $R((40,55,65,80))>R((30,40,40,50))$, $F E S_{3}=(40,55,65,80)$.

$$
\begin{aligned}
F E S_{4} & =F E S_{1} \oplus F E T_{14}=(0,0,0,0) \oplus(15,20,25,30) \\
& =(15,20,25,30)
\end{aligned}
$$

Table 1. The fuzzy activity time for each activity in the ground operation network shown as Figure 1 


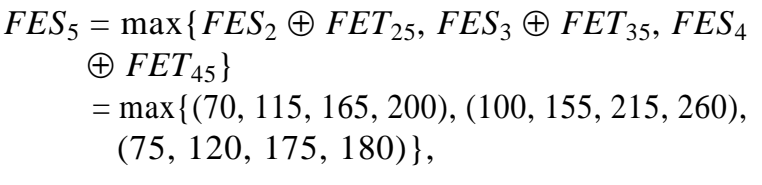

by Eq. (2) and taking $\beta=0.5306, F E S_{5}=(100,155,215$, 260).

Step 2. Set $F L F_{5}=(100,155,215,260)$ and calculate $F L F_{j}, j=4,3,2,1$ by using property 2 .

$$
\begin{aligned}
F L F_{4} & =F L F_{5} \ominus F E T_{45}=(100,155,215,260) \\
& \ominus(60,100,150,180)=(-80,5,115,200), \\
F L F_{3} & =F L F_{5} \ominus F E T_{35}=(100,155,215,260) \\
& \ominus(60,100,150,180)=(-80,5,115,200), \\
F L F_{2} & =\min \left\{F L F_{5} \ominus F E T_{25}, F L F_{3} \ominus F E T_{23}\right\} \\
& =\min \{(40,5,115,200),(-140,-45,75,170)\} .
\end{aligned}
$$

by Eq. (2) and taking $\beta=0.5306, F L F_{2}=(-140,-45,75$, $100)$.

$$
\begin{gathered}
F L F_{1}=\min \left\{F L F_{4} \ominus F E T_{14}, F L F_{3} \ominus F E T_{13}, F L F_{2}\right. \\
\left.\ominus F E T_{12}\right\}=\min \{(-110,-20,95,185), \\
(-130,-35,75,170),(-160,-60,60,160)\},
\end{gathered}
$$

by Eq. (2) and taking $\beta=0.5306, F L F_{1}=(-160,-60,60$, 160).

Step 3. Calculate $F T S_{i j}$ with respect to each activity by property 3 .

$$
\begin{aligned}
F T S_{12} & =F L F_{2} \ominus\left(F E S_{1} \oplus F E T_{12}\right) \\
& =(-140,-45,75,170) \ominus((0,0,0,0) \\
& \oplus(10,15,15,20))=(-160,-60,60,160) \\
F T S_{13} & =F L F_{3} \ominus\left(F E S_{1} \oplus F E T_{13}\right) \\
& =(-80,5,115,200) \ominus((0,0,0,0) \\
& \oplus(30,40,40,50))=(-130,-35,75,170) \\
F_{14} & =F L F_{4} \ominus\left(F E S_{1} \oplus F E T_{14}\right) \\
& =(-80,5,115,200) \ominus((0,0,0,0) \\
& \oplus(15,20,25,30))=(-110,-20,95,185) \\
F T S_{23} & =F L F_{3} \ominus\left(F E S_{2} \oplus F E T_{23}\right) \\
& =(-80,5,115,200) \ominus((10,15,15,20) \\
& \oplus(30,40,50,60))=(-160,-60,60,160) \\
F T S_{25} & =F L F_{5} \ominus\left(F E S_{2} \oplus F E T_{25}\right) \\
& =(100,155,215,260) \ominus((10,15,15,20) \\
& \oplus(60,100,150,180))=(-100,-10,100,190) \\
F T S_{35} & =F L F_{5} \ominus\left(F E S_{3} \oplus F E T_{35}\right)
\end{aligned}
$$

$=(100,155,215,260) \ominus((40,55,65,80)$

$\oplus(60,100,150,180))=(-160,-60,60,160)$

$$
\begin{aligned}
\text { FTS }_{45} & =F L F_{5} \ominus\left(\text { FES }_{4} \oplus \text { FET }_{45}\right) \\
& =(100,155,215,260) \ominus((15,20,25,30) \\
& \oplus(60,100,150,180))=(-110,-20,95,185)
\end{aligned}
$$

Step 4. Find all the possible paths and calculate FCPM $\left(P_{k}\right)$ by using property 4 .

$$
P=\{(1,2,5),(1,2,3,5),(1,3,5),(1,4,5)\}
$$

1. Let path $P_{1}=(1,2,5)$, then $\operatorname{FCPM}\left(P_{1}\right)$

$=F T S_{12} \oplus F T S_{25}=(-160,60,60,160)$

$\oplus(-100,-10,100,190)=(-260,-70,160,350)$

2. Let path $P_{2}=(1,2,3,5)$, then $\operatorname{FCPM}\left(P_{2}\right)$

$=F T S_{12} \oplus F T S_{23} \oplus F T S_{35}=(-160,-60,60,160)$

$\oplus(-160,-60,60,160) \oplus(-160,-60,60,160)$

$=(-480,-180,80,480)$

3. Let path $P_{3}=(1,3,5)$, then $\operatorname{FCPM}\left(P_{3}\right)$

$=$ FTS $_{13} \oplus$ FTS $_{35}=(-130,-35,75,170)$

$\oplus(-160,-60,60,160)=(-290,-95,135,330)$

4. Let path $P_{4}=(1,4,5)$, then $\operatorname{FCPM}\left(P_{4}\right)$

$=$ FTS $_{14} \oplus F T S_{45}=(-110,-20,95,185)$

$\oplus(-110,-20,95,185)=(-220,-40,190,370)$

Step 5. Find the fuzzy critical path by using theorem 1 and taking $\beta=0.5306$, the ranking value of $\operatorname{FCPM}\left(P_{i}\right), i=1,2,3,4$ can be obtained:

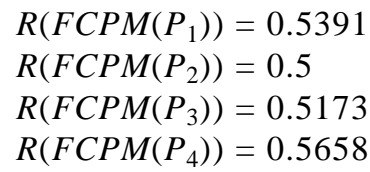

Since $R\left(F C P M\left(P_{2}\right)\right)<R\left(F C P M\left(P_{3}\right)\right)<R(F C P M$ $\left.\left(P_{1}\right)\right)<R\left(F C P M\left(P_{4}\right)\right)$, the fuzzy critical path is $P_{2}$ and the airport's ground operation completion time is approximately between 155 and 215 minutes, i.e., (100, $155,215,260)$. Further, the grade of membership that the airport's ground operation completed time can be obtained. For example, the grade of membership that the airport's ground operation completion time being within 100 minutes is 0.3125 . As it can be seen from this analysis, the path where cargo ground service operations influence combination carriers is $P_{2}$. If carriers are assigned through this path for ground service operations to export by authorization, the average export operations time wasted will be at its longest. This is to say that if the efficiency of cargo ground services operations is to be raised; improving the efficiency obtained 
from these processes needs to be done. This can also be seen from a report of the Taipei customs office "Air Cargo Clearance Automation" (a brief introduction to cargo clearance automation), because integrated carriers only offer C1 (inspection-exempt cargo clearance) and $\mathrm{C} 3$, (cargo clearance with inspection) whereas combination carriers offer C2 (cargo clearance with document approval) in addition to $\mathrm{C} 1$ and $\mathrm{C} 3$.

No single entity-airline can assure a level of quality without recognition of the links in the chain of global logistic service. On an international basis, one link common to all shipments is customs. Since customs has had little attention as a link in the service chain. When comparing the working hours of customs to other government service entities, such as police, hospitals and airlines companies all operate seven days a week, 24 hours a day. The customs service hours for cargo reflect government office hours rather than those of a service organization. Consequently, most airport combination carriers' cargo terminals are unable to provide a service level similar to that provided by integrated carriers (e.g. FedEx, UPS, DHL), which is a standardized, simplified, quick response airfreight service standard. Therefore, only when customs collectively moves to meet the needs of the marketplace can the airports of air cargo ground service is totally improved and secure.

\section{CONCLUDING REMARKS}

If an airport terminal's internal operations and service system are inefficient, or if the operational procedures are ineffective, these factors can contribute to flight delays for airlines which may prove very costly in a long-run. This highlights the importance of the appropriate terminal operational procedures and performance indicators in airport management. Despite this importance, there has been scant attention given to this aspect in airport management context. Though there have been appeals to avoid the delays and inefficiencies experienced in airside, landside, and airlines' operations, the available operation measurement models to cut down airlines' cost only provide vague and uncertain decision-making information. An airport is an interconnected set of physical facilities and components. For an airport to function efficiently, the capacities of each of these elements must be matched. Relief of a bottleneck in one part of the airport will not have the desired effect on improving overall through-traffic unless other parts are capable of absorbing a greater influx of traffic. Apart from this, the goodness-of-fit test for the activity times to satisfy beta distribution is not only a troublesome process, but may yield disappointing results as well. Hence, the conventional precision-based/ random-oriented project analysis tends to be less effective in conveying reliable information in an imprecise and fuzzy decision environment. This paper uses a fuzzy critical path algorithm to tackle the problem in fuzzy airport's ground operation decision analysis. The method takes into account the rating attitude (optimistic/ pessimistic) of decision makers. Thus, by conducting fuzzy or non-fuzzy activity time assessments, decisionmakers can automatically obtain the fuzzy critical path. Therefore, only when customs collectively moves to meet the needs of the marketplace can the airports of air cargo ground service is totally improved and secure.

\section{REFERENCES}

1. Ashford, N., Martin, S.H.P., and Moore, C.A., Airport Operations, McGraw-Hill, New York (1997).

2. Baker, C. and O'toole, K., "Negative Growth," Airlines Business, Jun., pp. 51-56 (2002).

3. Barrett, S.D., "Airport Competition in the Deregulated European Aviation Market," Journal of Air Transport Management, Vol. 6, pp. 13-27 (2000).

4. Bolat, A., "Theory and Methodology Procedures for Providing Robust Fate Assignments for Arriving Aircrafts," European Journal of Operation Research, Vol. 120, pp. 63-80 (2000).

5. Bortolan, G. and Degani, R., "A Review of Some Methods for Ranking Fuzzy Subsets," Fuzzy Sets and Systems, Vol. 15, pp. 1-19 (1985).

6. Chanas, S. and Zielinski, P., "Critical Path Analysis in the Network with Fuzzy Activity Times," Fuzzy Sets and Systems, Vol. 122, pp. 195-204 (2001).

7. Chen, S.H., "Ranking Fuzzy Numbers with Maximizing and Minimizing Set," Fuzzy Sets and Systems, Vol. 17, pp. 113-129 (1985).

8. Danganzo, C.F., "Reversibility of the Time-Dependent Shortest Path Problem," Transportation Research Part B, Vol. 36, pp. 665-668 (2002).

9. Dempsey, P.S., Gesell, L.E., and Crandall, R.L., Airline Management: Strategies for the 21st Century, Coast Air Publications, AZ (1997).

10. Forster, P.W. and Regan, A.C., "Electronic Integration in the Air Cargo Industry: An Information Processing Model of On-Time Performance," Transportation Journal, Vol. 40, No. 4, pp. 46-61 (2001).

11. Han, T.C., Lin, K., and Liang, G.S., "The Operation Demands Analysis of Taiwanese International Airport Cargo Terminal," Civil Aviation Journal Quarterly, Vol. 5, No. 2, pp. 1-26 (2003).

12. Hansen, M., "Micro-Level Analysis of Airport Delay Externalities Using Deterministic Queuing Models: A Case Study," Journal of Air Transport Management, Vol. 8, pp. 73-87 (2002).

13. Kim, K. and Park, K.S., "Ranking Fuzzy Numbers with Index of Optimism," Fuzzy Sets and Systems, Vol. 35, 
pp. $143-150$ (1990)

14. Liang, G.S. and Han, T.C., "Critical Path Analysis Based on Fuzzy Concept," International Journal of Information and Management Sciences, Vol. 15, No. 4, pp. 2940 (2004).

15. Lijesen, M.G., Rietveld, P., and Nijkamp, P., "How Do Carriers Price Connecting Flights? Evidence from Intercontinental Flights from Europe," Transportation Research Part E, Vol. 38, pp. 239-252 (2002).

16. Mohleji, S.C., "A Route-Oriented Planning and Control Concept for Efficient Flight Operations at Busy Airports," Control Engineering Practice, Vol. 4, No. 8, pp. 1143-1151 (1996).

17. Morris, L.S. and Ga, M., "Airport Adviser Listens to Travel Concerns," Knight Rider Tribune Business News, Washington, Jan. 23 (2003).

18. Nasution, S.H., "Fuzzy Critical Path Method," IEEE Transportation Systems Man Cybernet, Vol. 24, pp. 4857 (1994).

19. Slyeptsov, A.I. and Tyshchuk, T.A., "A Method of Computation of Characteristics of Operations in a Problem of Fuzzy Network," Cybernetics and Planning and Management System Analysis, Vol. 39, No. 3, pp. 367378 (2003).
20. Wells, A.T., Air Transportation - A Management Perspective, Wadsworth, New York (1999).

21. Wu, C.L. and Caves, R.E., "Modelling of Aircraft Rotation in a Multiple Airport Environment," Transportation Research Part E, Vol. 38, pp. 265-277 (2002).

22. Yan, S., Shieh, C.Y., and Chen, M., "A Simulation Framework for Evaluating Airport Gate Assignments," Transportation Research Part A, Vol. 36, pp. 885-898 (2002).

23. Zadeh, L.A., "Fuzzy Sets," Information and Control, Vol. 8, pp. 138-353 (1965).

24. Zadeh, L.A., "The Concept of a Linguistic Variable and Its Application to Approximate Reasoning I, II, III," Information Sciences, Vol. 8, pp. 199-249, pp. 301-357; Vol. 9, pp. 43-80 (1975).

25. Zhang, A., "Analysis of an International Air-Cargo Hub: the Case of Hong Kong," Journal of Air Transport Management, Vol. 9, pp. 123-138 (2003).

26. Zhang, A. and Zhang, Y., "Airport Charges, Economic Growth, and Cost Recovery," Transportation Research Part E, Vol. 37, pp. 25-33 (2001).

27. Zhang, A. and Zhang, Y., "A Model of Air Cargo Liberalization: Passenger vs. All-Cargo Carriers," Transportation Research Part E, Vol. 38, pp. 175-191 (2002). 